\title{
Antitumor activity of pamidronate in breast cancer cells transformed by low doses of $\alpha$-particles and estrogen in vitro
}

\author{
RICHARD PONCE-CUSI ${ }^{1}$ and GLORIA M. CALAF ${ }^{1,2}$ \\ ${ }^{1}$ Instituto de Alta Investigación, Universidad de Tarapacá, Arica, Chile; \\ ${ }^{2}$ Center for Radiological Research, Columbia University Medical Center, New York, NY, USA
}

Received January 23, 2015; Accepted March 2, 2015

DOI: 10.3892/ijo.2015.2955

\begin{abstract}
Human breast cancer is a major cause of global morbidity and mortality in women and it is a process that involves numerous molecular and cellular alterations attributed to environmental substances and agents such as hormones. Bisphosphonates, such as pamidronate, are potent antiresorptive drugs used to the treatment of metabolic bone disease, exerting anti-proliferative, anti-migratory and apoptotic effects. The aim of this study was to evaluate gene and protein expression involved in these processes. An in vitro model was developed with the MCF-10F immortalized breast epithelial cell line exposed to low radiation doses of high LET (linear energy transfer) $\alpha$-particles $(150 \mathrm{keV} / \mu \mathrm{m})$ and cultured in the presence of $17 \beta$-estradiol (estrogen). This model consisted of the following cell lines: i) MCF-10F, normal; ii) Alpha3, non-malignant; iii) Alpha5, pre-tumorigenic, and iv) Tumor2, derived from Alpha5 injected into the nude mice. Our previous results have shown that Alpha5 and Tumor2 increased cell proliferation, anchorage independency, invasive capabilities and tumor formation in nude mice in comparison to control. Expression of the gene (RT-qPCR) and protein (western blotting, flow cytometry) was measured. The results indicated that pamidronate decreased invasion, migration and Rho-A, c-Ha-ras, p53, Serpin-1, Caveolin-1, Bcl-xL and $N F \kappa B$ gene and protein expression. Thus, it seems that pamidronate may impinge upon cellular proliferation, invasion, metastasis and apoptosis and it may exert antitumor activity in breast cancer cells transformed by low doses of $\alpha$-particles and estrogen in vitro.
\end{abstract}

\section{Introduction}

Breast cancer is one of the most common types of cancer in women. Women with advanced breast cancer ultimately

Correspondence to: Dr Gloria M. Calaf, Instituto de Alta Investigación, Universidad de Tarapacá, Calle Antofagasta \#1520, Arica 8097877, Chile

E-mail: gmc24@columbia.edu

Key words: pamidronate, Rho-A, c-Ha-ras, p53, Serpin-1, caveolin-1, Bcl-xL, NFאB, apoptosis, breast cancer cell lines develop bone metastasis which increases significantly morbidity and mortality. Approximately 20-30\% of human tumors contain mutated versions of Ras proteins. Ras is an important signal transducing protein for growth factor activated pathways. Normal Ras binds GTP and in the GTP-bound state interacts with numerous effectors including the Raf proto-oncogene kinase and phosphatidylinositol-3-kinase (PI3K). The Rho family of GTPases includes the Rho, Rac and CDC42 genes (1). While the functions of these GTPases have not been clarified, it appears that the Rho proteins play a role in regulating cell morphology $(2,3)$.

The $p 53$ gene is known as the guardian of the genome (4). A major biological function of p53 is to respond to stress signals and activate the transcription of downstream target genes involved in important cellular mechanisms such as cell cycle control, DNA repair and apoptosis. The p53 has two very distinct roles in cell cycle control mechanisms. The first is a protective (cytostatic) one in which p53 arrests cells in the G1 phase of the cell cycle upon sensing DNA damage. In a second role, p53 initiates apoptosis upon irreparable damage to the cell.

Serpins are serine protease inhibitors structurally conserved molecules encompassing nearly all branches of life (5). Among newly characterized serpin functions, regulation of cellular proliferation through apoptosis modulation and proteasome disturbance seem to play a major role. Accordingly, several serpins were found to be overexpressed in tumor cells. Indeed, apoptosis dysregulation is likely to be a cornerstone in both tumorigenesis and autoimmunity, since uncontrolled cellular viability results in tumor proliferation, while inefficient disposal of apoptotic debris may favor the rescue of auto-reactive immune cells.

Caveolin is a specialized lipid raft on the plasma membrane found in mesenchymal cells (6-9). The caveolin family consists of three members, caveolin-1 (cav-1), caveolin-2 and caveolin-3. Cav-1 is widely expressed in various tissues. Previous studies demonstrated the essential role of caveolin in a number of human diseases including cancer (6). Previously, both the epithelial and stromal caveolin have been detected in breast cancer patients to determine the prognosis (9).

Apoptosis has been defined as a genetic death program leading to the ordered destruction of cellular components, while membrane integrity is maintained (10). The balance between pro- and anti-apoptotic signals guarantee biological 
homeostasis and its disturbance is highly related to malignant transformation (10). Two distinct major pathways have been described that lead to activation of aspartate-specific cysteine proteases (caspases) that finally mediate apoptosis. The extrinsic pathway involves binding of extracellular death ligands to specific cell surface death receptors and formation of the death-inducing signaling complex. The intrinsic pathway depends on mitochondria, is initiated by intracellular signals such as DNA damage and needs activation of the tumor suppressor p53 (11).

$\mathrm{NF} \kappa \mathrm{B}$ is a family of 5 transcriptional factors including $\mathrm{p} 50$, p52, p65 (Rel-A), Rel-B and c-Rel (12). NFкB is recognized as a key positive regulator of cancer cell proliferation and survival via its ability to transcriptionally activate many prosurvival and anti-apoptotic genes such as XIAP, Bcl-2, Bcl- $x \mathrm{~L}$, IkB- $a, c I A P 1, c I A P-2$ and survivin $(12,13)$.

Bisphosphonates are potent antiresorptive drugs used to the treatment of metabolic bone disease. It has been shown that these compounds have direct effects on tumor cells in vitro, including the induction of apoptosis in human myeloma cell lines $(14,15)$. Pamidronate is a member of nitrogen-containing bisphosphonates used in the treatment of bone metastasis of breast and prostate cancer. It has been reported as a mechanism of action inhibiting the mevalonate pathway which is a requirement for the prenylation (activation) of small GTP-binding proteins such as farnesylpyrophospate synthase and/or geranylgeranylpyrophosphate synthase thus blocking the generation of isoprenoid compounds, farnesylpyrophosphate and/or geranylgeranylpyrophosphate. The aim of this study was to evaluate antitumor activity of pamidronate in breast cancer cell model with cells transformed by low doses of $\alpha$-particles and estrogen in vitro (16).

\section{Materials and methods}

Breast cancer cell lines. The spontaneously immortalized breast epithelial cell line, MCF-10F cells was grown in DMEM/F-12 (1:1) medium supplemented with antibiotics $100 \mathrm{U} / \mathrm{ml}$ penicillin, $100 \mu \mathrm{g} / \mathrm{ml}$ streptomycin, $2.5 \mu \mathrm{g} / \mathrm{ml}$ amphotericin B (all from Life Technologies, Grand Island, NY, USA) and $10 \mu \mathrm{g} / \mathrm{ml}$ and $5 \%$ equine serum (Biofluids, Rockville, MD, USA), $0.5 \mu \mathrm{g} / \mathrm{ml}$ hydrocortisone (Sigma, St. Louis, MO, USA) and $0.02 \mu \mathrm{g} / \mathrm{ml}$ epidermal growth factor (Collaborative Research, Bedford, MA). An in vitro experimental breast cancer model developed by exposure of the immortalized human breast epithelial cell line was used. MCF-10F was exposed to low doses of high LET (linear energy transfer) $\alpha$-particle radiation $(150 \mathrm{keV} / \mu \mathrm{m})$ and subsequent growth in the presence or absence of $17 \beta$-estradiol at $10^{-8} \mathrm{M}$ (E or Estrogen) (Sigma-Aldrich). This model consisted of human breast epithelial cells in different stages of transformation: i) a control cell line, MCF-10F; ii) a non-malignant cell line, named Alpha3; iii) a malignant and tumorigenic, cell line named Alpha5 and iv) Tumor2 derived from cells originated from a tumor after injection of Alpha5 cells into the nude mice (16).

MTT assay. The metabolic activity of living cells, as indicator of viability, was determined by 3-(4,5-dimethylthiazol-2-yl)-2, 5-diphenyltetrazolium bromide (MTT) assay. MCF-10F cell line $\left(5 \times 10^{4}\right)$ was seeded in 24-well microplates and incubated in culture medium for 24 and $48 \mathrm{~h}$ at $37^{\circ} \mathrm{C}$ and $5 \% \mathrm{CO}_{2}$. After incubation, MCF-10F was treated with a series of concentrations $(10,30,50$ and $80 \mu \mathrm{M})$ of pamidronate (Sigma-Aldrich, Oakville, ON, Canada). After the treatment of cells, reduction of MTT was determined following manufacturer's instructions. The treatment groups were compared with the control group and the results were expressed as percentage of viable cells.

Cell invasion and migration assays. Invasiveness and migration was carried out as previously described (16) using modified Boyden's chambers (Corning, New York, NY, USA) constructed with multiwell cell culture plates and cell culture inserts. The upper chambers of Transwells with 8- $\mu \mathrm{m}$ membrane pores were pre-coated with $60 \mu 1$ Matrigel matrix gel (BD Biosciences) at least $1 \mathrm{~h}$ before seeding the cells studied. A total of $3 \times 10^{4}$ cells in $100 \mu \mathrm{l}$ of medium without fetal bovine serum (FBS) was added into the upper chambers and $600 \mu \mathrm{l}$ of medium with $10 \%$ FBS was placed to lower chambers as chemoattractant. Twelve hours later, the upper chambers were removed from lower chambers and then wiped using cotton swabs. The invaded and migrated cells were fixed using methanol at room temperature for $15 \mathrm{~min}$, visualized and quantified using crystal violet. Three fields of each chamber were photographed (magnification, $x 40$ ) and the results are from duplicate chambers and are presented as mean \pm SEM. The experiment was independently repeated at least twice.

Western blot analysis. Cells were lysated with $1 \mathrm{ml}$ lysis buffer (pH 7.2) (Tris Base $(50 \mathrm{mM})$, EDTA $(1 \mathrm{mM}), \mathrm{NaCl}$ (100 mM), PMSF (1 mM), ortovanadate (1 mM), Triton $\mathrm{X}-100(0.1 \%)$ and centrifuged $(10,000 \mathrm{rpm}$ x $10 \mathrm{~min})$. The supernatant with cellular proteins were dissolved in SDS-PAGE sample solution (60 mM) Tris, pH 6.5, $10 \%$ (w/v) glycerol, $5 \%(\mathrm{w} / \mathrm{v}) \beta$-mercaptoethanol, $20 \%$ (w/v) SDS, and $0.025 \%(\mathrm{w} / \mathrm{v})$ bromophenol blue and denatured by boiling ( $2 \times 5 \mathrm{~min})$, sonication $(2 \times 5 \mathrm{~min}$ in a sonication bath), and vortex mixing $(2 \times 30 \mathrm{seg})$. The total amount of protein was $40 \mu \mathrm{g}$ in each lane with standard protein markers (Bio-Rad Laboratories, Hercules, CA, USA). After fractionation by SDS-PAGE on gels $(7 \times 14 \mathrm{~cm})$, proteins were electro-blotted onto PVDF membrane (Amersham Biosciences, Amersham, UK) using a blotting apparatus (Bio-Rad Laboratories). Prestained SDS-PAGE (Standards) blots were blocked for $2 \mathrm{~h}$ in $10 \%$ defatted dry milk-TBS-0.1\% Tween and then incubated for $2 \mathrm{~h}$ at room temperature with corresponding primary antibodies (1:200) Rho-A (26C4) sc-418 and $\beta$-actin (C4) sc-47778 followed by incubation with secondary peroxidase-conjugated mouse IgG (1:5000) (Cell Signaling, CA, USA) in $5 \%$ defatted dry milk-TBS- $0.1 \%$ Tween. All steps were performed at room temperature, and blots were rinsed between incubation steps with TBS-0.1\% Tween. Cell blots were probed with mouse anti-actin antibody as control. Immunoreactive bands were visualized by using the ECL ${ }^{\mathrm{TM}}$ Western Blotting Detection Reagent detection method (Amersham, Dübendorf, Switzerland) and exposure of the membrane to X-ray film. Protein determination was performed using the Bicinchoninic Acid Method (Bio-Rad 
Table I. Primers for genes selected to develop cDNA probes.

\begin{tabular}{|c|c|c|}
\hline Gene name & Product length (bp) $)^{\mathrm{a}}$ & Primer sequence ${ }^{b}$ \\
\hline Rho-A & 140 & $\begin{array}{l}\text { F: CCATCATCCTGGTTGGGAAT } \\
\text { R: CATGTACCCAAAAGCGCCA }\end{array}$ \\
\hline$c-H a-r a s$ & 112 & $\begin{array}{l}\text { F: CCAGTACAGGGAGCAGAT } \\
\text { R: GAGCCTGCCGAGATTCCACA }\end{array}$ \\
\hline p53 & 128 & $\begin{array}{l}\text { F: CCTCAGCATCTTATCCGAGTGG } \\
\text { R: TGGATGGTGGTACAGTCAGAGC }\end{array}$ \\
\hline Serpin-1 & 101 & $\begin{array}{l}\text { F: GAGACAGGCAGCTCGGATTC } \\
\text { R: GGCCTCCCAAAGTGCATTAC }\end{array}$ \\
\hline Caveolin-1 & 79 & $\begin{array}{l}\text { F: AACGATGACGTGGTCAAGATTG } \\
\text { R: TCCAAATGCCGTCAAAACTGT }\end{array}$ \\
\hline$B c l-x L$ & 211 & $\begin{array}{l}\text { F: CTGAATCGGAGATGGAGACC } \\
\text { R: TGGGATGTCAGGTCACTGAA }\end{array}$ \\
\hline$N F \kappa B(\operatorname{RelA})$ & 114 & $\begin{array}{l}\text { F: ATCTGCCGAGTGAACCGAAACT } \\
\text { R: CCAGCCTGGTCCCGTGAAA }\end{array}$ \\
\hline$\beta$-actin & 569 & $\begin{array}{l}\text { F: ACTACCTCATGAAGATCCTC } \\
\text { R: TAGAAGCATTTGCGGTGGACGATGG }\end{array}$ \\
\hline
\end{tabular}

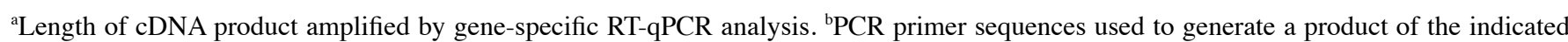
size, listed in 5' to 3' orientation. F, forward; R, reverse.

Laboratories) and BSA as the standards. Experiments were performed three times.

RNA extraction and $c D N A$ synthesis. Total RNA from control and treated cells were isolated using TRIzol reagent (Invitrogen Corp., Carlsbad, CA, USA) according to the manufacturer's recommendations. Total RNA $(2 \mu \mathrm{g})$ was reverse-transcribed to cDNA using High capacity cDNA Reverse Transcription kit (Applied Biosystems, Carlsbad, CA, USA) and 10 units of RNase inhibitor (Applied Biosystems).

$R T$ - $q P C R$. An aliquot of cDNA $(2 \mu 1)$ was used in $20 \mu 1$ qPCR reaction containing SYBR Green PCR Master Mix (Agilent, La Jolla, CA, USA) and $5 \mu \mathrm{M}$ of each primer for the target genes Rho-A, c-Ha-ras, p53, Serpin-1, Caveolin-1, $B c l-x L$ and $N F \kappa B$ or reference gene ( $\beta$-actin). Table I shows the primers for the gene selected to develop cDNA probes. The reaction was performed in a CFX 96 Touch Real-Time PCR Detection Systems (Bio-Rad Laboratories) with the following conditions: $95^{\circ} \mathrm{C}$ for $10 \mathrm{~min}$ and 40 cycles of a 2-step program of $95^{\circ} \mathrm{C}$ for $10 \mathrm{sec}$ and $61^{\circ} \mathrm{C}$ for $45 \mathrm{sec}$ when fluorescence-reading occurs. After amplification, PCR product was monitored through dissociation curve analysis (measurement of fluorescence during an increasing heating of $2{ }^{\circ} \mathrm{C} / \mathrm{min}$ from 61 to $95^{\circ} \mathrm{C}$ ). At this step, undesirable DNA contamination (if present) could be detected since primers were designed to encompass an intron. Reactions were performed in triplicate and the threshold cycle $(\mathrm{Ct})$ was obtained using Bio-Rad CFX Manager 2.1 software and the averaged gene expression was normalized using the reference housekeeping gene $\beta$-actin and relative expres- sion level was calculated. Relative expression was normalized to the average in normal breast cells.

Flow cytometry. Phosphatidylserine (PS) is located inside the cell membrane in normal cells and is transferred to the surface during the early stage of cell apoptosis. Annexin $\mathrm{V}, \mathrm{a} \mathrm{Ca}^{2+}$ dependent phospholipid binding protein, has a strong binding affinity for PS. Thus, an Annexin V-FITC/7-AAD staining kit was used to assess pamidronate-induced cell apoptosis. MCF-10F, Alpha5 and Tumor 2 cell lines were cultured to $70 \%$ confluence, then pamidronate with indicated concentrations was added. After $48 \mathrm{~h}$, cells were harvested and washed twice with pre-cold PBS and then resuspended in $1 \mathrm{X}$ binding buffer at a concentration of $1 \times 10^{6}$ cells $/ \mathrm{ml}, 100 \mu \mathrm{l}$ of such solution ( $1 \times 10^{5}$ cells) was mixed with $10 \mu \mathrm{l}$ of Annexin V-FITC and $20 \mu \mathrm{l}$ of 7-amino actinomycin D (7-AAD) (Beckman Coulter, Fullerton, CA, USA) according to the manufacturer's instructions. The mixed solution was incubated at room temperature $\left(25^{\circ} \mathrm{C}\right.$ ) away from light for $15 \mathrm{~min}$. Then $400 \mu \mathrm{l}$ of $1 \mathrm{X}$ dilution buffer was added to each tube. Analysis was performed by Beckman Coulter FC500 Flow Cytometry System with CXP software (Beckman Coulter) within $1 \mathrm{~h}$.

Statistical analysis. Numerical data were expressed as the average \pm standard error of the mean (SEM). Comparison between treated groups and controls was carried out by ANOVA and Dunnet's test. A p $<0.05$ and $\mathrm{p}<0.01$ were considered to be significant. Lethal dose at $50 \%\left(\mathrm{LD}_{50}\right)$ was calculated by a non-linear regression curve using GraphPad Prism 5.0 for Windows (GraphPad Software, San Diego, CA, USA). 

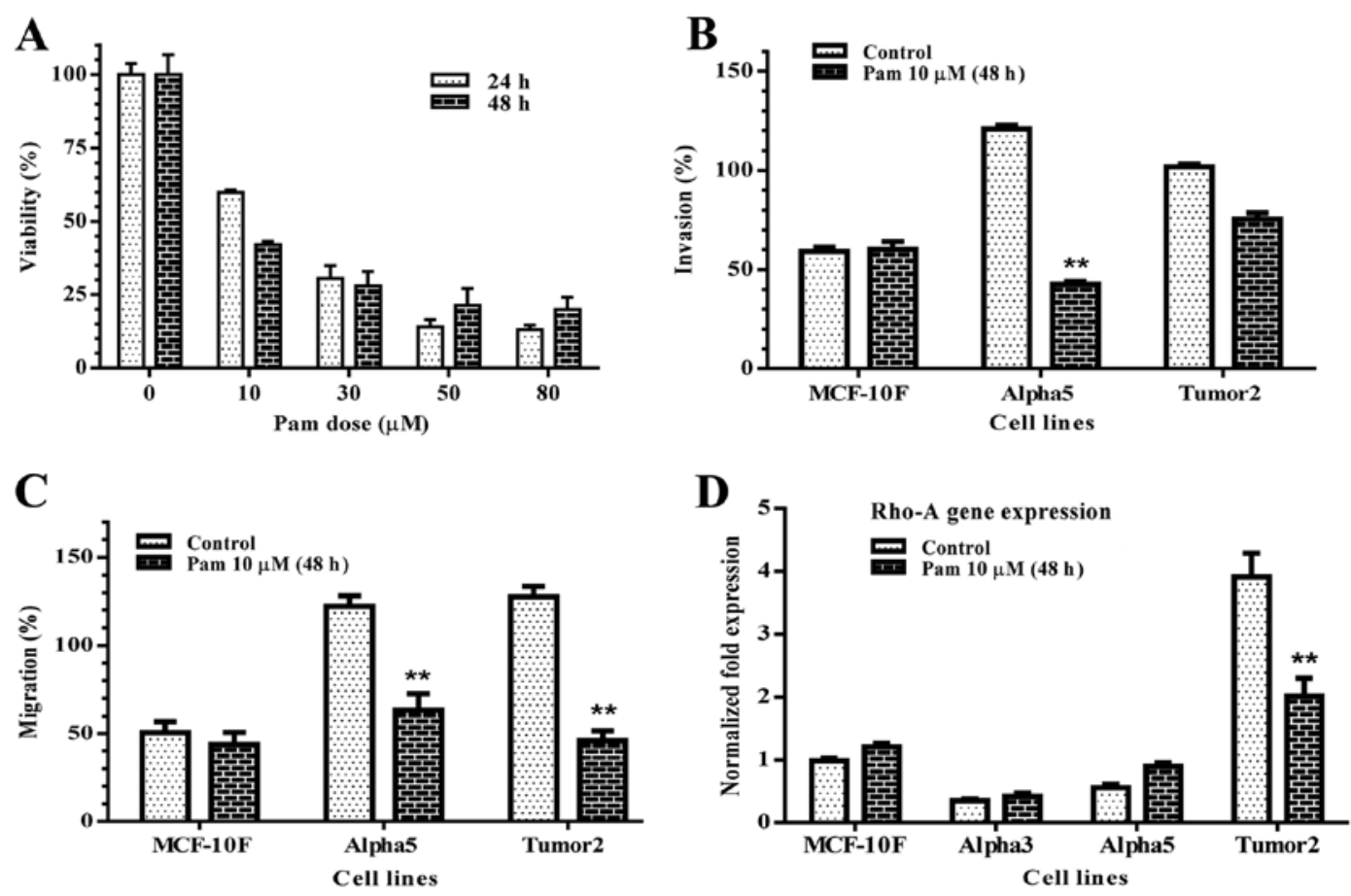

Figure 1. (A) Effect of pamidronate on cell viability. MCF-10F cell line was treated with different doses of pamidronate (from 0 to $80 \mu \mathrm{M}$ ) and incubated for 24 and $48 \mathrm{~h}$. It was determined by using the MTT assay and an automated cell counter. (B) Cell invasion and (C) migration: effect of pamidronate $(10 \mu \mathrm{M} / 48 \mathrm{~h})$ in MCF-10F, Alpha5 and Tumor 2 cell lines was quantified by microscopy (x40 magnification). These experiments were carried out as described previously (16). Bars represent the mean \pm SEM of three independent experiments. ${ }^{*} \mathrm{p}<0.05,{ }^{* * *} \mathrm{p}<0.01$ vs. control group and their counterparts. (D) Rho-A gene expression: Effect of pamidronate was evaluated in MCF-10F, Alpha5 and Tumor2 cell lines by RT-qPCR. $\beta$-actin was used as an endogenous control gene. Data are presented as means \pm SEM of three independent experiments. ${ }^{*} \mathrm{p}<0.05,{ }^{* *} \mathrm{p}<0.01$ vs. counterparts.

A

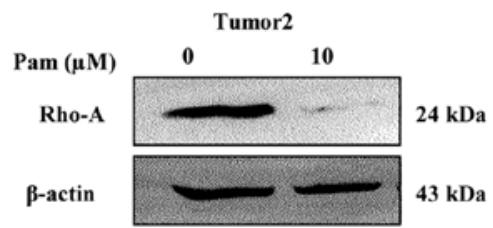

B

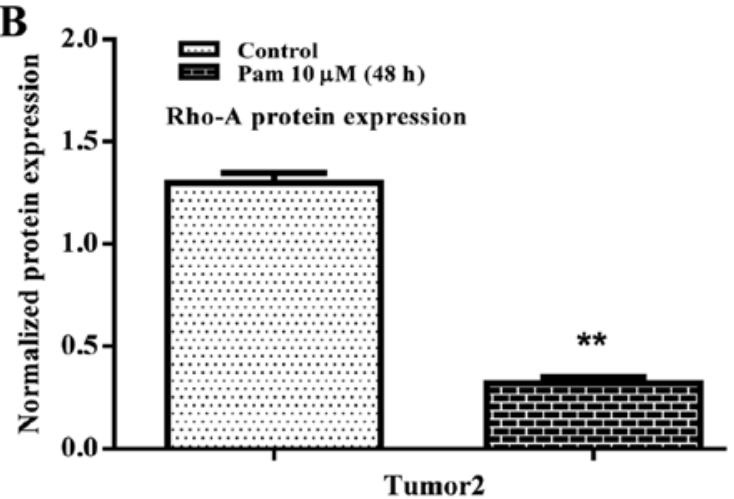

Cell lines
C

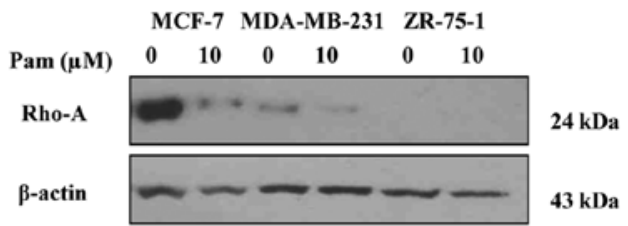

D

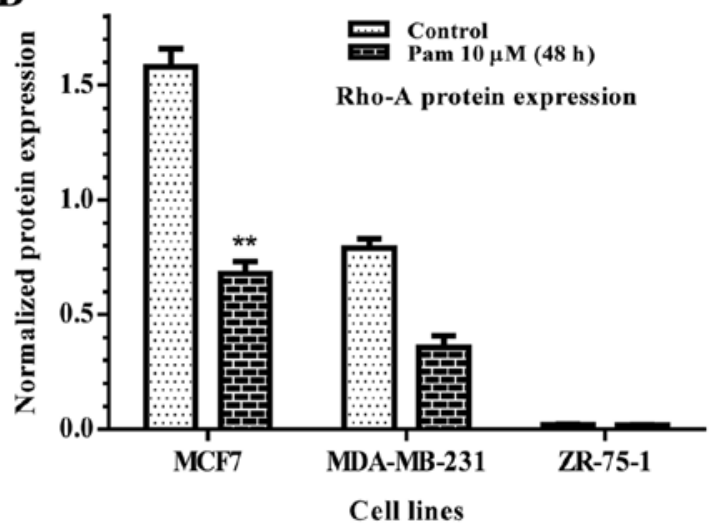

Figure 2. Rho-A protein expression: effect of pamidronate in Tumor2 cell line (A and B); MCF-7, MDA-MB-231 and ZR-75-1 (C and D) determinated by western blot analyses. $\beta$-actin was used as control for loading. Band density of the specific protein was analyzed with Adobe Photoshop program and the results were expressed as average density to $\beta$-actin. Graphs represent the relative grade of luminiscence to assess the protein level of the cell lines. Bars represent the mean \pm SEM of three independent experiments. ${ }^{* *} \mathrm{p}<0.01$ vs. counterpart.

\section{Results}

The effect of pamidronate in cell viability in vitro was analyzed using the MTT assay. Treatment with increasing concentrations of pamidronate ranging from 0 to $80 \mu \mathrm{M}$ resulted in a concentration-dependent decrease in cell number after 24 and $48 \mathrm{~h}$ in MCF-10F cell line. Results in Fig. 1A showed that the mean $\mathrm{LD}_{50}$ was $10 \mu \mathrm{M}$. Then, all the experiments were carried out with $10 \mu \mathrm{M}$ pamidronate. Migration and invasion assays were performed to analyze the effect of pamidronate on 

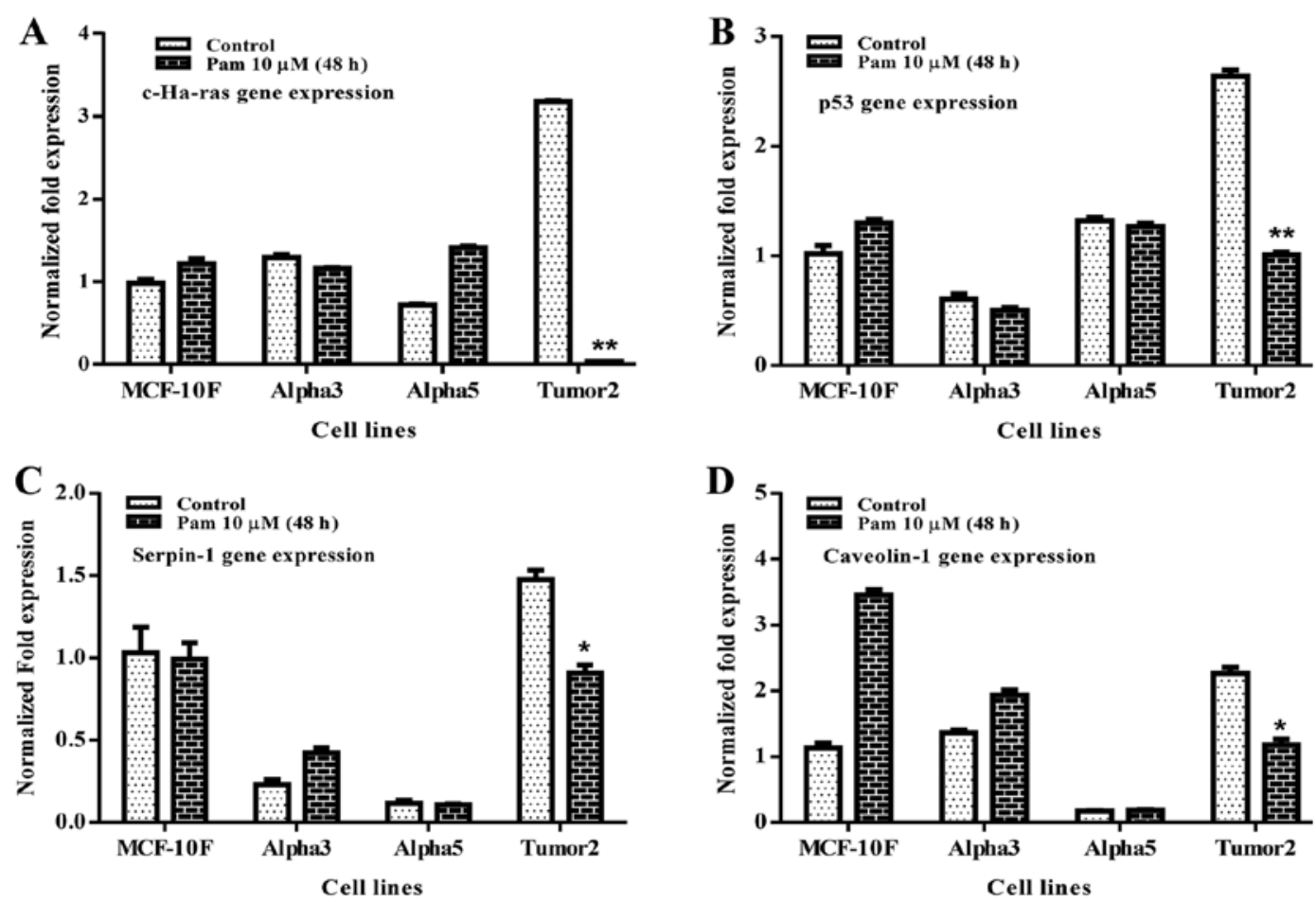

Figure 3. Effect of pamidronate on (A) c-Ha-ras, (B) p53, (C) Serpin-1 and (D) Caveolin-1 gene expression by RT-qPCR in MCF-10F, Alpha3, Alpha5 and Tumor 2 cell lines. $\beta$-actin was used as an endogenous control gene. Bars represent the mean \pm SEM of three independent experiments. ${ }^{*} \mathrm{p}<0.05,{ }^{* *} \mathrm{p}<0.01 \mathrm{vs}$. counterparts.

MCF-10F, Alpha5 and Tumor2 cell lines where basic fibroblast growth factor (b-FGF) induced the migration of such cells. Results indicated that pamidronate significantly inhibited $(p<0.01)$ the $b$-FGF-induced migration and invasion in both Alpha5 and Tumor2 cell lines (Fig. 1B and C) compared to the control MCF-10F. These results suggest that pamidronate influences cell migration and invasion.

Rho-A is a small GTPase protein known to regulate the actin cytoskeleton in the formation of stress fibers and it is generally distributed in the nuclei of cancer cells. Rho-A gene and protein expression were studied by RT-qPCR and western blot analysis. Results of the experiments indicated that pamidronate significantly decreased Rho-A gene expression of the malignant and tumorigenic cell line Tumor2 $(\mathrm{p}<0.01)$ in comparison with its counterpart (Fig. 1D). In addition, Rho-A protein expression was evaluated in Tumor2 cell line and other malignant cell lines such as MCF7, MDA-MB-231 and ZR-75-1. It was found that pamidronate significantly decreased Rho-A protein expression in Tumor2 (Fig. 2A and $\mathrm{B})$ and MCF7 and MDA-MB-231 $(\mathrm{p}<0.01)$ in comparison to their counterparts. There was no Rho-A protein expression in ZR-75-1 (Fig. 2C and D).

Analysis by real-time PCR indicated that pamidronate significantly decreased gene expression of $c$-Ha-ras $(\mathrm{p}<0.01)$, p53 ( $\mathrm{p}<0.01)$, Serpin-1 $(\mathrm{p}<0.05)$ and Caveolin-1 $(\mathrm{p}<0.05)$ in Tumor 2 cell line in comparison to its counterparts. However, Alpha3 and Alpha5 cell lines did not show any significant difference with their counterparts (Fig. 3).

The apoptotic effects of pamidronate on MCF-10F, Alpha5 and Tumor 2 cell lines analyzed by flow cytometry showed $6.4 \%$ of apoptotic cells in the control MCF-10F. On the other hand, Alpha5 and Tumor2 showed 10.4 and $14.5 \%$, respectively
(Fig. 4). Results indicated that $B c l-x L(\mathrm{p}<0.01)$ and $N F \kappa B$ $(\mathrm{p}<0.01)$ were significantly reduced in Tumor2 in comparison to its counterparts (Fig. 5A and B).

\section{Discussion}

In the present study, the in vitro effects of pamidronate in breast cancer cell lines were evaluated by several parameters. Pamidronate showed direct antitumor and apoptotic activities in breast cancer cell lines, which is in agreement with results from previous studies (17), highlighting the role of signal transduction pathways controlled by the Rho family of small GTPases (18). Treatment of pamidronate decreased Rho-A gene and protein expression in Tumor2, MCF7, MDA-MB231 in comparison to their counterparts. The inhibition of Rho proteins might provide a possibility to reduce metastasis through interference with this pathway according to invasion and migration assays where pamidronate reduced their percentage in Alpha5 and Tumor2 cell lines. Recent studies have indicated that pamidronate induced apoptotic effects in myeloma cells in vitro (19-27). The involvement of the inhibitory effect of pamidronate on isoprenoid biosynthesis in induction of apoptosis could be tested by using farnesol and geranylgeraniol to circumvent the blockade of geraniol synthesis. Geranylgeraniol was more potent in abolishing pamidronate-induced apoptosis than farnesol (19). These authors demonstrated that geranylgeraniol reduced apoptosis by approximately $75 \%$, suggesting geranylgeranylated proteins such as Rho proteins were main target of the pamidronate effect.

Pamidronate decreased $\mathrm{c}$-Ha-ras gene expression in Tumor2 cell line in comparison to its counterpart. Authors 


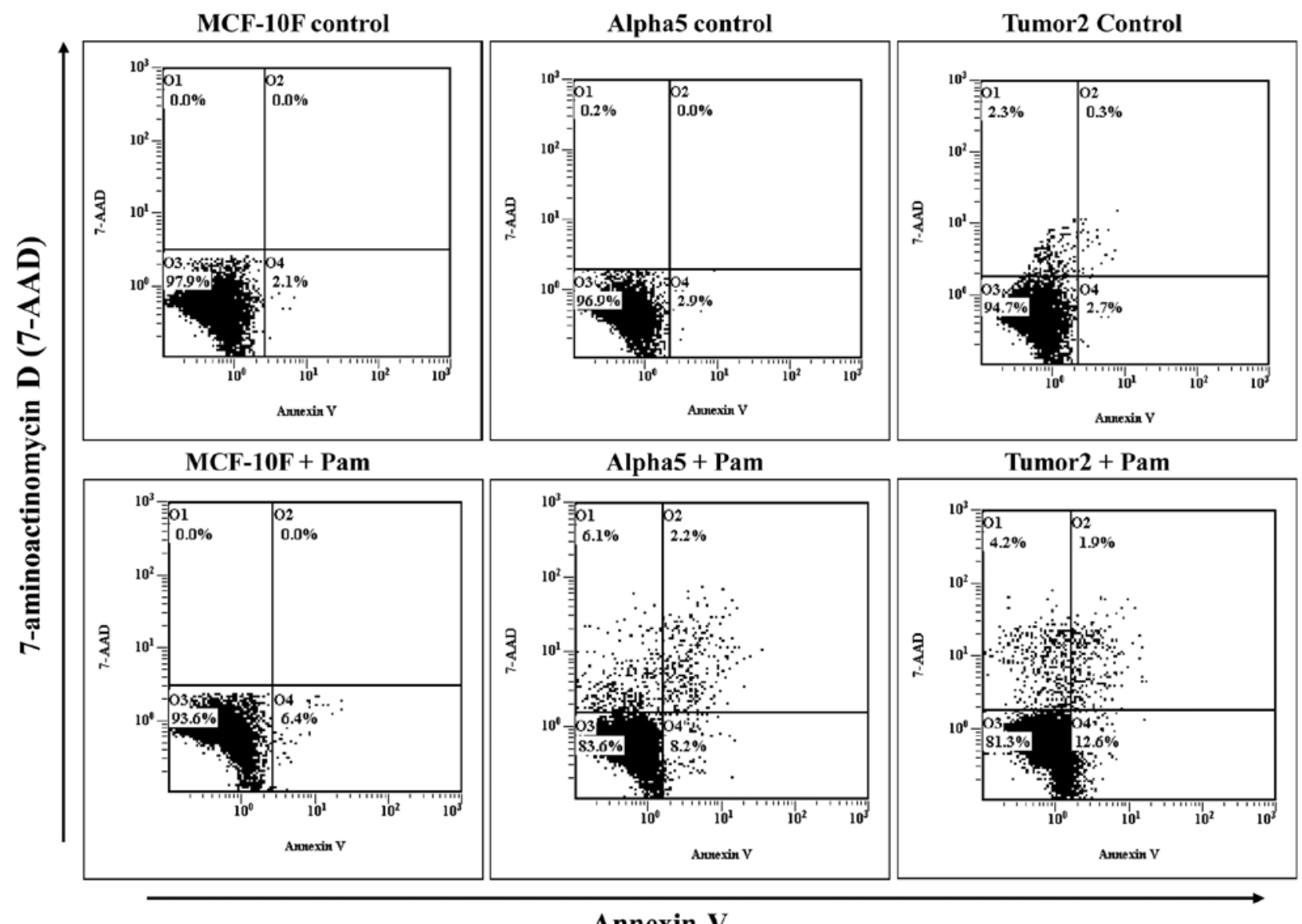

Figure 4. Flow cytometric analysis for apoptosis of breast cancer cells: apoptotic effects of pamidronate $(10 \mu \mathrm{M} / 48 \mathrm{~h})$ were evaluated in MCF-10F, Alpha5 and Tumor 2 cell lines compared with their counterparts. Upper left quadrant (O1) indicates cells undergoing necrosis; upper right quadrant (O2), cells at the end stage of apoptosis; lower left quadrant (O3), cells that are viable, or no measurable apoptosis and lower right quadrant (O4), cells undergoing apoptosis. The percentage of the cells in apoptosis was determined by CXP software.
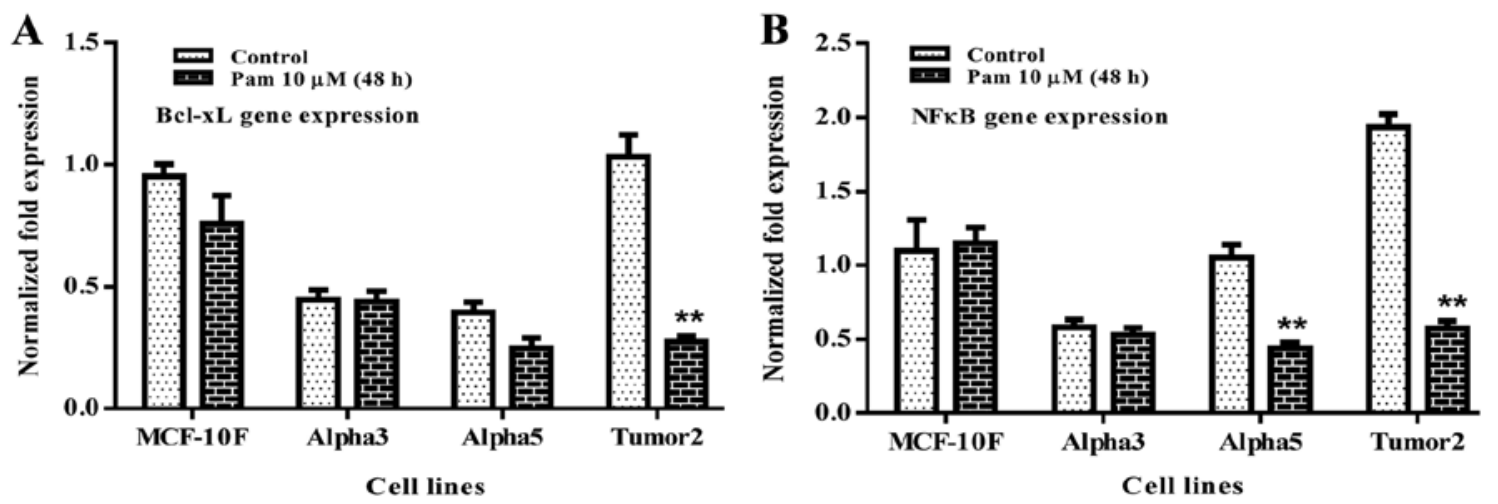

Figure 5. Effect of pamidronate on (A) $B c l-x L$ and (A) $N F \kappa B$ gene expression in MCF-10F, Alpha3, Alpha5 and Tumor2 cell lines by RT-qPCR. $\beta$-actin was used as an endogenous control gene. Bars represent the mean \pm SEM of three independent experiments. ${ }^{* *} \mathrm{p}<0.01$ vs. counterparts.

have reported that c-Ha-ras expression in myeloma cells was valuable in predicting the therapeutic effects of pamidronate. Others demonstrated that resistance to pamidronate may result from low levels of GTPase-activating proteins, such as N-ras and H-ras in tumor cells (20). Pamidronate has been shown to be a highly effective inhibitor of human cell proliferation by inactivating the Ras/ERK pathway since it induced apoptosis by inhibiting farnesylproteins containing Ras protein $(20,21)$. The prenylation of monomeric G-proteins such as the members of the Ras superfamily Rho proteins was reduced by bisphosphonate treatment $(22,23)$. It seems that effects of $\mathrm{H}$-ras on cell motility appeared to be through activation of a MAP kinase cascade, presumably via the Ras effector Raf (24). Pamidronate and zoledronic acid induced apoptosis and growth inhibition in epidermoid cancer cells that occur together with depression of ras signaling of ERK and Akt survival pathways (25).

The present results indicated that p53 gene expression decreased by pamidronate in malignant and tumorigenic cell 
line Tumor2 in comparison to its counterpart. Other authors have indicated that pamidronate inhibited cell growth and induced apoptosis in human melanoma cells in vitro (22). Susceptibility to pamidronate did not correlate to CD95 ligand sensitivity or p53 mutational status. Other studies (21) showed that p-JNK diminished while p53 was unaltered following pamidronate treatment, ruling out activation of apoptosis via these two pathways.

Regarding the genes related to metastasis, Serpin- 1 and Caveolin-1 were evaluated where pamidronate decreased their gene expression in Tumor 2 cell line in comparison to their counterparts. The mitogenic activity of the $\mathrm{C}$-terminal section of serpin A1 is localized within the last 26 amino acids (25). The activity of the peptide was sensitive to PKC inhibitors and T24 phosphorylation and resulted in increased activity in MCF7 cells. Serpin A1 plays a key role in the neutralization of neutrophil elastase. Tumor growth and metastasis of breast cancer cells could be enhanced at sites of high proteolytic activity, in which there is an excess of serine proteases over serpin A1 (24). In vitro studies have shown that both stromal and epithelial cav-1 play a protective role against mammary hyperplasia and tumorigenesis in breast cancer $(8,9)$.

Genes related to apoptosis such as $B c l-x L$ decreased its gene expression of the malignant and tumorigenic Tumor 2 cell line by the effect of pamidronate. Another key positive regulator of cancer cell proliferation and survival is $\mathrm{NF \kappa B}(12,13)$ which it has the ability to transcriptionally activate many pro-survival and anti-apoptotic genes such as $B c l-x L$. It was observed that $N F \kappa B$ gene expression was decreased in Tumor 2 cell line in comparison to its counterpart. It can be concluded that pamidronate may exert antitumor activity in breast cancer cells transformed by low doses of $\alpha$-particles and estrogen in vitro by downregulating $B c l-x L$ and $N F \kappa B$ gene expression.

\section{Acknowledgements}

The secretarial assistance of Leodán Crispin is greatly appreciated. This study was supported by Grant support FONDECYT \#1120006 (G.M.C) and MINEDUC-UTA (G.M.C).

\section{References}

1. Hall A: The cellular functions of small GTP-binding proteins. Science 249: 635-640, 1990.

2. Ridley AJ and Hall A: The small GTP-binding protein rho regulates the assembly of focal adhesions and actin stress fibers in response to growth factors. Cell 70: 389-399, 1992.

3. Ridley AJ, Paterson HF, Johnston CL, Diekmann D and Hall A: The small GTP-binding protein rac regulates growth factorinduced membrane ruffling. Cell 70: 401-410, 1992.

4. Lane DP: Cancer. p53, guardian of the genome. Nature 358: 15-16, 1992.

5. Gatto M, Iaccarino L, Ghirardello A, Bassi N, Pontisso P, Punzi L, Shoenfeld Y and Doria A: Serpins, immunity and autoimmunity: Old molecules, new functions. Clin Rev Allergy Immunol 45: 267-280, 2013.

6. Hnasko R and Lisanti MP: The biology of caveolae: Lessons from caveolin knockout mice and implications for human disease. Mol Interv 3: 445-464, 2003.

7. Witkiewicz AK, Dasgupta A, Sammons S, Er O, Potoczek MB, Guiles F, Sotgia F, Brody JR, Mitchell EP and Lisanti MP: Loss of stromal caveolin-1 expression predicts poor clinical outcome in triple negative and basal-like breast cancers. Cancer Biol Ther 10: $135-143,2010$.
8. Sotgia F, Schubert W, Pestell RG and Lisanti MP: Genetic ablation of caveolin-1 in mammary epithelial cells increases milk production and hyper-activates STAT5a signaling. Cancer Biol Ther 5: 292-297, 2006.

9. Williams TM, Sotgia F, Lee H, Hassan G, Di Vizio D, Bonuccelli G, Capozza F, Mercier I, Rui H, Pestell RG, et al: Stromal and epithelial caveolin-1 both confer a protective effect against mammary hyperplasia and tumorigenesis: Caveolin-1 antagonizes cyclin D1 function in mammary epithelial cells. Am J Pathol 169: 1784-1801, 2006.

10. Reed JC: Apoptosis mechanisms: Implications for cancer drug discovery. Oncology (Williston Park) 18 (Suppl 10): 11-20, 2004.

11. Riedl SJ and Shi Y: Molecular mechanisms of caspase regulation during apoptosis. Nat Rev Mol Cell Biol 5: 897-907, 2004.

12. Sethi G, Ahn KS and Aggarwal BB: Targeting nuclear factor-kappa B activation pathway by thymoquinone: Role in suppression of antiapoptotic gene products and enhancement of apoptosis. Mol Cancer Res 6: 1059-1070, 2008.

13. Dolcet X, Llobet D, Pallares J and Matias-Guiu X: NF- $\kappa B$ in development and progression of human cancer. Virchows Arch 446: 475-482, 2005.

14. Shipman R, Schraml P, Moch H, Colombi M, Sauter G, Mihatsch $\mathrm{M}$ and Ludwig C: p53 protein accumulation and p53 gene alterations (RFLP, VNTR and p53 gene mutations) in noninvasive versus invasive human transitional bladder cancer. Int J Oncol 10: 801-806, 1997.

15. Donehower LA, Godley LA, Aldaz CM, Pyle R, Shi YP, Pinkel D, Gray J, Bradley A, Medina D and Varmus HE: The role of p53 loss in genomic instability and tumor progression in a murine mammary cancer model. Prog Clin Biol Res 395: 1-11, 1996.

16. Calaf GM and Hei TK: Establishment of a radiation- and estrogeninduced breast cancer model. Carcinogenesis 21: 769-776, 2000.

17. Wada A, Fukui K, Sawai Y, Imanaka K, Kiso S, Tamura S, Shimomura I and Hayashi N: Pamidronate induced anti-proliferative, apoptotic, and anti-migratory effects in hepatocellular carcinoma. J Hepatol 44: 142-150, 2006

18. Clemons MJ, Dranitsaris G, Ooi WS, Yogendran G, Sukovic T, Wong BY, Verma S, Pritchard KI, Trudeau M and Cole DE: Phase II trial evaluating the palliative benefit of second-line zoledronic acid in breast cancer patients with either a skeletalrelated event or progressive bone metastases despite first-line bisphosphonate therapy. J Clin Oncol 24: 4895-4900, 2006.

19. Riebeling C, Forsea AM, Raisova M, Orfanos CE and Geilen CC: The bisphosphonate pamidronate induces apoptosis in human melanoma cells in vitro. Br J Cancer 87: 366-371, 2002.

20. Zhang PL, Lun M, Siegelmann-Danieli N, Blasick TM and Brown RE: Pamidronate resistance and associated low ras levels in breast cancer cells: A role for combinatorial therapy. Ann Clin Lab Sci 34: 263-270, 2004.

21. Zhang PL, Quiery AT Jr, Blasick TM and Brown RE: Morphoproteomic expression of H-ras (p21ras) correlates with serum monoclonal immunoglobulin reduction in multiple myeloma patients following pamidronate treatment. Ann Clin Lab Sci 37: 34-38, 2007.

22. Nguyen DH, Catling AD, Webb DJ, Sankovic M, Walker LA, Somlyo AV, Weber MJ and Gonias SL: Myosin light chain kinase functions downstream of Ras/ERK to promote migration of urokinase-type plasminogen activator-stimulated cells in an integrin-selective manner. J Cell Biol 146: 149-164, 1999.

23. Oxford G and Theodorescu D: Ras superfamily monomeric $\mathrm{G}$ proteins in carcinoma cell motility. Cancer Lett 189: 117-128, 2003.

24. Caraglia M, D'Alessandro AM, Marra M, Giuberti G, Vitale G, Viscomi C, Colao A, Prete SD, Tagliaferri P, Tassone P, et al: The farnesyl transferase inhibitor R115777 (Zarnestra) synergistically enhances growth inhibition and apoptosis induced on epidermoid cancer cells by Zoledronic acid (Zometa) and Pamidronate. Oncogene 23: 6900-6913, 2004.

25. Congote LF and Temmel N: The C-terminal 26-residue peptide of serpin A1 stimulates proliferation of breast and liver cancer cells: Role of protein kinase C and CD47. FEBS Lett 576: 343-347, 2004.

26. Aparicio A, Gardner A, Tu Y, Savage A, Berenson J and Lichtenstein A: In vitro cytoreductive effects on multiple myeloma cells induced by bisphosphonates. Leukemia 12: 220-229, 1998.

27. Senaratne SG, Pirianov G, Mansi JL, Arnett TR and Colston KW: Bisphosphonates induce apoptosis in human breast cancer cell lines. Br J Cancer 82: 1459-1468, 2000. 